\title{
Effects of Washing Media and Storage Condition on the Color of Milkfish Meat Paste
}

\author{
Wen-Lee Chen,${ }^{* 1, \dagger}$ Chau-Jen Chow, ${ }^{* 2}$ and Yoshihiro Ochiai ${ }^{* 3}$ \\ ${ }^{*}$ Foo Yin Junior College of Nursing and Medical Technology, Ta-Liao Hsiang, Kaohsiung 811, \\ Taiwan, R.O.C. \\ ${ }^{*_{2}}$ National Kaohsiung Institute of Marine Technology, Kaohsiung 811, Taiwan, R.O.C. \\ ${ }^{*}$ Laboratory of Food Science, Faculty of Education, Ibaraki University, Mito 310, Japan
}

(Received November 21, 1995)

\begin{abstract}
Fresh samples of milkfish were stored in ice for up to two weeks or frozen at $-20^{\circ} \mathrm{C}$ for up to two months. At due time intervals, the dorsal part of ordinary muscle excised was subjected to washing by various media (water, $40 \mathrm{~mm}$ phosphate buffers of $\mathrm{pH}$ 5.6-8.0, alkaline wash), and the effects of washing media on the extracting efficiency of pigment (myoglobin) and the tristimulus color values ( $\mathbf{L}, \mathbf{a}$ and b) of the extract and the meat paste (washed mince) were investigated. The results obtained showed that the pigment extracting efficiency decreased during ice or frozen storage. On the other hand, as the pH values of washing media were raised, the $\mathbf{L}$ values of both the extract and washed mince decreased, while $\mathbf{a}$ and $\mathbf{b}$ values became higher for the extract and tended to be lower for the washed mince.
\end{abstract}

Key words: milkfish, kamaboko, washing, storage, color, meat paste

\section{Introduction}

The milkfish Chanos chanos Forskal is one of the tropical fishes, and has traditionally been cultivated in Taiwan, but the recent establishment of cultivating techniques in deep freshwater has expanded the production of milkfish greatly. The harvest of milkfish, which used to be around $20 \sim 30$ thousand tons, increased to 90 thousand tons in $1990 .^{1)}$ Such a rapid increase in production, however, caused a drop in its commercial value. ${ }^{2)}$ Therefore, it is necessary to develop new techniques in order to raise the evaluation of milkfish products.

Generally, milkfish is not accepted by consumers as it is, because there are many tiny bones in the muscle. Thus, only the belly portion is usually used, while the bony dorsal portion is removed of the skin, bones and connective tissue, and ground into paste (surimi) for fish balls. Since the color of milkfish flesh is light pink due to the presence of myoglobin, the products turn grayish when heated. Even though the milkfish products show high gel strength, the dark color is actually a serious deterrent for human consumption.

Concerning the characteristics of milkfish muscle from biochemical aspects, several reports deal with the properties and denaturation profiles of myosin and actomyo$\sin ^{3-7)}$ However, little information is available on milkfish kamaboko. Recently, Ko and Liou ${ }^{8)}$ reported that the gel strength of milkfish kamaboko was increased by washing up to about 2.5 times.

For milkfish, the most urgent problem is to remove the pigment (mostly myoglobin) from the flesh as much as possible so that the products become acceptable to con- sumers. We therefore studied the effects of washing on the efficiency of pigment extraction and the color of meat paste (washed mince) from fresh, ice- and frozen-stored milkfish to search for a way to improve the quality (mainly the color) of milkfish kamaboko. Attempts were also made to elucidate the effect of washing media on the quality of kamaboko from fresh fish.

\section{Materials and Methods}

\section{Materials}

Fresh specimens of milkfish (in rigor mortis) were purchased from the Nan-Tzu Wholesale Market, Kaohsiung, Taiwan. The body weight and total length of the specimens were in the range of $0.6-0.9 \mathrm{~kg}$ and $30-40 \mathrm{~cm}$, respectively. The specimens were divided into three groups; the first group was used immediately ("fresh" fish), the second group was stored in ice for up to 2 weeks (ice-stored fish), and the third group was frozen at $-60^{\circ} \mathrm{C}$ for $24 \mathrm{~h}$ and then stored at $-20^{\circ} \mathrm{C}$ for up to 2 months until used (frozen-stored fish). The fish was stored in plastic bags without any processing. Just before use, the frozen samples in bags were thawed by tap water as quickly as possible. In the following experiments, only the ordinary muscle of the dorsal portion was used.

\section{Extraction of Pigment}

Pigment (myoglobin) was extracted according to the methods of Warriss" and Chow et al. ${ }^{10)}$ Minced muscle was homogenized with a Nihonseiki AM-5 homogenizer $(1,000 \mathrm{rpm}$ for $5 \mathrm{~min})$ once with 10 volumes of the following ice-cold washing media: deionized water; $40 \mathrm{mM} \mathrm{Na}$ phosphate buffers (pH 5.6, 6.0, 6.4, 6.8, 7.2, 7.6, and 8.0);

† To whom correspondence should be addressed. 
and alkaline wash $\left(0.2 \% \mathrm{NaHCO}_{3}-0.15 \% \mathrm{NaCl}\right)$. The homogenates were centrifuged at 7,000 rpm (ca. 5,000 $\times g)$ for 15 min with a Hitachi CR20B2 centrifuge, and the supernatants (referred to as "extract") obtained were used for the measurement of pigment content and color. The moisture of the precipitate (meat paste, referred to as "washed mince") was determined, and was adjusted to $82 \%$ by adding appropriate volumes of deionized water, and prior to the color measurement, was mixed by a silent cutter as described later.

\section{Measurement of Pigment Content}

In order to estimate the extractable amount of pigment, the myoglobin content in the extract was measured according to the method of Chow et al. ${ }^{10)}$ The extract was filtered through a Toyo $5 \mathrm{C}$ filter paper, further filtered through a Millipore membrane filter (pore size $0.2 \mu \mathrm{m}$ ). Two milliliters of the filtrate thus obtained was mixed with $2 \mathrm{~m} l$ of $1 \mathrm{M} \mathrm{Na}, \mathrm{K}$-phosphate buffer $(\mathrm{pH} \mathrm{7.0)}$ and $50 \mu \mathrm{l}$ of $5 \%$ $\mathrm{NaNO}_{2}$, allowed to stand for $1 \mathrm{~min}$, and the absorbance was measured at $540 \mathrm{~nm}\left(\mathrm{~A}_{540}\right)$ after the addition of $50 \mu \mathrm{l}$ of $1 \% \mathrm{KCN}$. The molar extinction coefficient used for cyanmetmyoglobin was $11,300{ }^{11)}$ The pigment concentration was determined by the following equation, using 15,900 daltons as the molecular weight of myoglobin (W.-L. Chen, unpublished data),

$$
\text { Pigment content }(\mathrm{mg} / \mathrm{m} l)=\frac{\mathrm{A}_{540} \times 2}{11,300} \times 15,900
$$

\section{Color Measurement}

The color of the extract and washed mince was measured with a Tokyo Denshoku TC-3600 colorimeter. The instrument was calibrated beforehand with a white standard disc (X, 98.1; Y, 100; Z, 118.2). The results were expressed by the tristimulus values of the Hunter's color difference scale, $\mathbf{L}$ (lightness), $\mathbf{a}(+$, red; - , green) and $b$ $(+$, yellow; - , blue). Transmittance was measured for the extract in a cubic glass cell, while the reflectance was measured for the washed mince using a round glass cell. Measurements were carried out four times for each kamaboko gel and in duplicate for the washed mince, and only the average values were given. Standard deviations were negligible: less than 0.7 for $\mathbf{L}$ value, and less than 0.4 for a and $\mathbf{b}$ values.

\section{Measurement of Metmyoglobin to Total Myoglobin Ratio $(\mathrm{Met} M \mathrm{~B} \%)$}

MetMb\% was measured according to the method of Sano and Hashimoto ${ }^{12)}$ and Chow et al. ${ }^{10)}$ To the filtrate prepared as above was added an equal volume of $1 \mathrm{M} \mathrm{Na}$, $\mathrm{K}$-phosphate buffer ( $\mathrm{pH} 7.0$ ), then it was divided into three portions. To the first portion was added a trace amount of sodium hydrosulfite, bubbled with $\mathrm{CO}$ gas, and the absorbance at $568 \mathrm{~nm}$ was measured (designated as $\mathrm{A}_{1}$ ). The second portion was directly bubbled with $\mathrm{CO}$ gas and the absorbance at the same wavelength was measured $\left(A_{2}\right)$. To the third portion was added $0.05 \mathrm{~m} /$ of $2 \%$ potassium ferricyanide and the absorbance at $568 \mathrm{~nm}$ was measured $\left(\mathrm{A}_{3}\right)$. MetMb\% was calculated as follows:

$$
\text { MetMb } \%=\frac{A_{1}-A_{2}}{A_{1}-A_{3}} \times 100
$$

Measurements were performed in triplicate, and the mean values were given.

\section{Preparation of Kamaboko}

After washing once with 10 volumes of each medium, the moisture was adjusted to $82 \%$. The washed mince was then ground by a silent cutter (Ching-Sheng-Hao Metal Factory, Model K-3) with sequential addition of $2.2 \%$ $\mathrm{NaCl}, 0.6 \%$ monosodium glutamate, $3 \%$ sugar and $5 \%$ sweet potato starch. The ground mince was then transferred into the cubes $(21 \times 30 \times 3 \mathrm{~cm})$ and incubated at $40^{\circ}$ $\mathrm{C}$ for $1 \mathrm{~h}$ for setting, and subsequently cut into cubes $(3 \times 3 \times 3 \mathrm{~cm})$ and heated in a water bath at $90^{\circ} \mathrm{C}$ for 15 min. These setting and heating conditions were determined based on preliminary experiments to maximize the gel strength of kamaboko. The kamaboko thus prepared was cooled in ice immediately, contained in a plastic bag, and stored at $4^{\circ} \mathrm{C}$ overnight prior to the textural analyses as follows. ${ }^{13)}$

\section{Measurement of the Gel Strength of Kamaboko}

Gel strength of kamaboko was measured according to the method of Chow. ${ }^{14)}$ Kamaboko, cut into cubes $(2 \times 2 \times 2 \mathrm{~cm})$, was subjected to a rheometer (CR-200D, Sun Scientific Co.) equipped with a globular plunger ( 7 $\mathrm{mm}$ in diameter). The gel strength was expressed by maximum stress $(\mathrm{g})$ and deformation $(\mathrm{cm})$ at the breaking point. Determination was carried out 4 to 6 times for each sample, and the mean values and standard deviations were given.

\section{Folding Test}

The folding test of kamaboko was performed according to the method of Fujii, ${ }^{15)}$ and the results were graded as follows:

AA : no cracks when folded into quadrants;

A : no cracks when folded into semicircle;

B : cracks when folded into semicircle;

$C$ : broken into pieces when folded into semicircle.

\section{Measurement of the Expressible Water of Kamaboko}

In order to estimate the water-holding capacity of kamaboko, the amount of expressible water was determined according to the method of Jauregui et al. ${ }^{16}$ ) Kamaboko was cut into a slice $(0.5 \mathrm{~g}, 1 \mathrm{~mm}$ thick) and packed in a Toyo $4 \mathrm{~A}$ filter paper, and centrifuged at $16,000 \mathrm{rpm}$ (ca. $15,000 \times g$ ) for $15 \mathrm{~min}$ with a Hitachi CR20B2 centrifuge. The percentage of the weight loss was expressed as the amount of expressible water. Measurements were carried out 4 to 6 times, and the mean values and standard deviations were given.

\section{Determination of Moisture Content}

Moisture content was determined according to the AOAC method. ${ }^{17)}$ Determinations were done in triplicate.

\section{Measurement of $p H$}

The $\mathrm{pH}$ value of the extract obtained by washing was directly measured with a Corning $\mathrm{pH}$ meter 220 equipped 


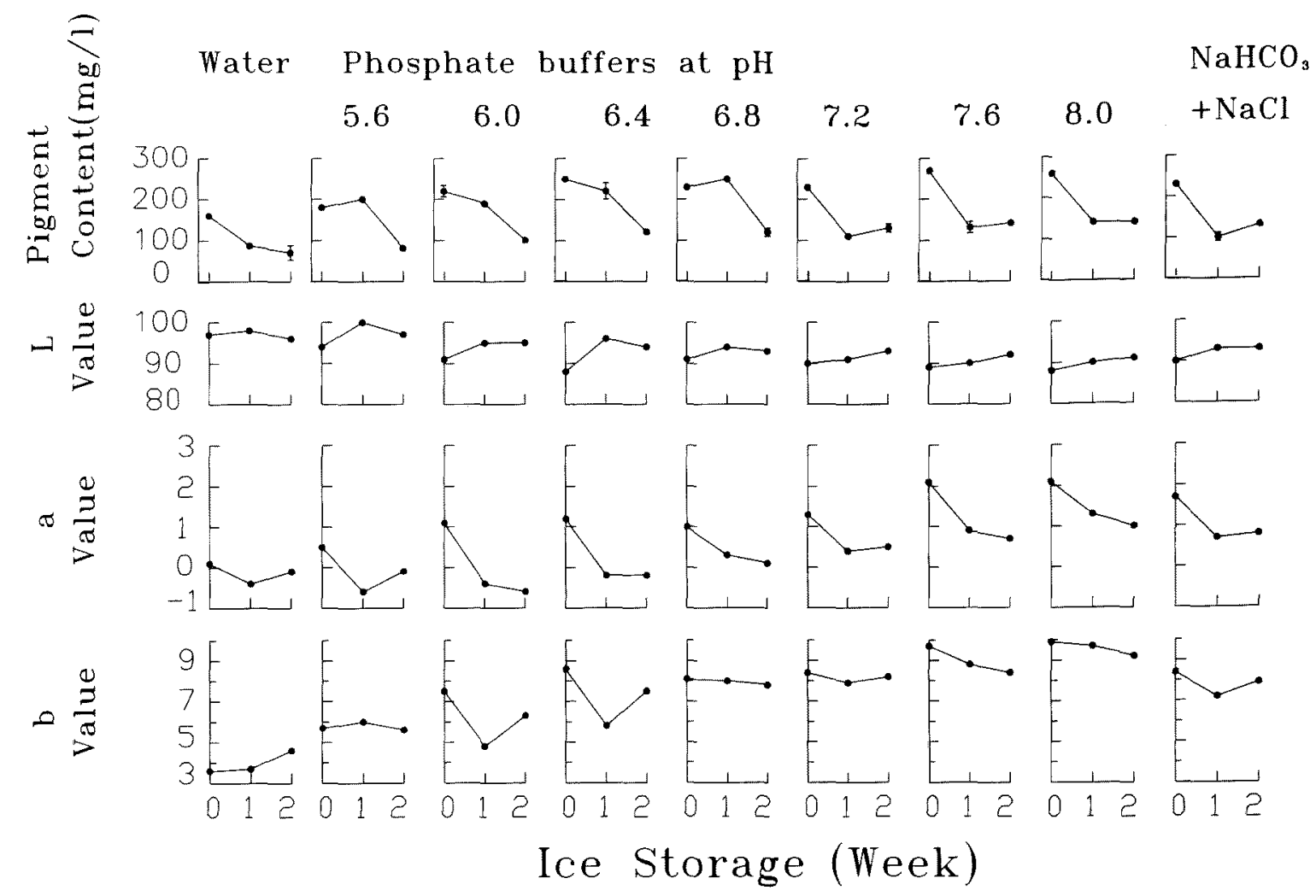

Fig. 1. Effects of washing media and storage period on the pigment content and Hunter's tristimulus values (L, a and b) of the extracts from icestored milkfish.

Table 1. Final pH of the extracts obtained by washing the fresh, ice-stored and frozen-stored milkfish

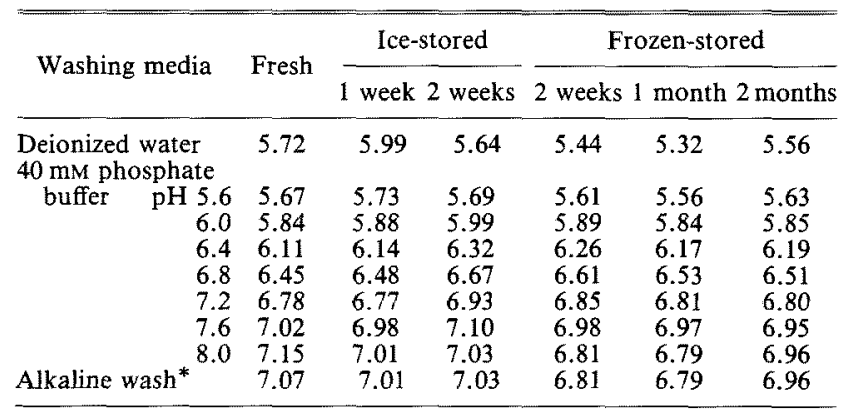

$* 0.2 \% \mathrm{NaHCO}_{3}-0.15 \% \mathrm{NaCl}$.

with a complex glass electrode.

\section{Results and Discussion}

\section{Effect of Washing Media on Ice-Stored Fish}

Muscles from the fresh and ice-stored fish were washed with various media, and the pigment contents and tristimulus values of the extract were examined (Fig. 1). The pH values of the extract from each sample after washing are shown in Table 1. Preliminary experiments revealed that the $\mathrm{pH}$ values of washed mince were almost the same as the respective values for the extract (the differences were generally less than 0.03 ). Even using $\mathrm{pH} 5.6-8.0$ phosphate buffers for washing, the $\mathrm{pH}$ values of the extract fell in the range of $\mathrm{pH}$ 5.7-7.2. This suggests that the milkfish muscle used had already turned acidic due to the accumulation of lactic acid and inorganic phosphate, which were produced through glycolysis and breakdown of ATP, respectively.

The extractable amount of pigment from fresh muscle was $150-280 \mathrm{mg} / l$. Myoglobin is a highly water-soluble protein, and the extracting efficiency from fresh sample (by washing at $\mathrm{pH} 7.6$ in this case) is considered to be close to the maximum. Taking the dilution ratio of the extract into consideration, myoglobin concentration in milkfish muscle is estimated to be around $300 \mathrm{mg} / 100 \mathrm{~g}$, which is quite a reasonable value for milkfish. On the other hand, it is quite difficult to determine the amount of insolubilized pigment in the washed mince.

The extracting efficiency was the lowest for washing by water. The usage of alkaline wash $\left(0.2 \% \mathrm{NaHCO}_{3}-0.15 \%\right.$ $\mathrm{NaCl}$ ) or phosphate buffers of $\mathrm{pH}$ 6.4-8.0 resulted in the higher efficiency of extraction. The extractable amount of pigment, however, decreased during the two weeks of ice storage (below $150 \mathrm{mg} / l$ ), suggesting that myoglobin was insolubilized during ice storage. The values of metmyoglobin formation ratio (metMb\%) were 19.1, 24.6 and $37.9 \%$ for the samples stored in ice for 0,1 and 2 weeks, respectively. Such an increase in metMb\% means that myoglobin oxidation proceeded in the muscle of milkfish during the ice storage. As reported previously, ${ }^{18}$ autoxidation of myoglobin is accompanied by insolubilization of the protein. It follows that insolubilization of myoglobin also 
steadily proceeded during ice storage of milkfish. This was also true for the case of round herring. ${ }^{10}$ )

The $\mathbf{L}$ value (lightness) tended to increase as the pigment content decreased. The $\mathbf{L}$ value turned out to be the highest in the case of washing by water. Washing by $\mathrm{pH}$ 5.6 buffer resulted in a similar $\mathbf{L}$ value ( $>94$ ), whereas, using phosphate buffers (pH6.0-8.0) and alkaline wash, $\mathbf{L}$ values were decreased to around 90 . It is clear that acidic media seem to have contributed to the lightening (whitening) of washed mince. On the other hand, a and $\mathbf{b}$ values of the extract from fresh fish were higher for alkaline media than for acidic media. The a value decreased moderately after one week of ice storage, but remained almost unchanged thereafter. The b value changed in a similar way to the a value, but under acidic $\mathrm{pH}$ (6.0 and 6.4), the values for the one-week stored sample were higher than those for the two-week stored one.

The tristimulus values of the washed mince from the icestored fish were clearly different from those of unwashed mince: $\mathbf{a}$ and $\mathbf{b}$ values of the washed mince were lower and the $\mathbf{L}$ value was higher (Fig. 2). It was thus suggested that the color of the mince could be improved by washing. It was observed that washing under higher $\mathrm{pH}$ resulted in lower $\mathbf{L}$ values. The $\mathbf{L}$ value tended to increase slightly during storage, though the extracting efficiency of pigment decreased during ice storage (Fig. 1). In the case of the washed mince, the a value increased after 1 week, but decreased after 2 weeks. The reason is not clear. The b value showed similar changes to those for a value (except at $\mathrm{pH} 7.2$ and 7.6), but generally, the higher the $\mathrm{pH}$ value of the washing media, the lower the $\mathbf{b}$ values became. Chow et al. ${ }^{(9)}$ found that, during ice storage of tuna meat, $\mathbf{L}$ and $\mathbf{b}$ values increased and the a value decreased along with the increase in metMb\%. They also suggested that myoglobin autoxidation was accelerated under acidic $\mathrm{pH}$, causing the increase in $\mathbf{L}$ and $\mathbf{b}$ values and decrease in the $\mathbf{a}$ value. ${ }^{10)}$ In the case of milkfish, however, the changes in a and $\mathbf{b}$ values were far from those reported for tuna meat. The reasons for such differences between the two fish species could be ascribed to those in the minimum muscle $\mathrm{pH}$ after death and myoglobin content.

\section{Effect of Washing Media on Frozen-Stored Fish}

The $\mathrm{pH}$ values of the respective extract obtained by washing the frozen-stored milkfish are shown in Table 1. The values were slightly lower than those for fresh and icestored samples. This is supposed to be due to thaw rigor, which accelerated the breakdown of ATP.

The pigment content in the extract from the frozenstored fish tended to decrease during storage (Fig. 3). Washing by water and acidic buffers resulted in a lower efficiency of pigment extraction. However, as the $\mathrm{pH}$ of the wash was raised, the extractability was increased. Though the pigment content sharply decreased only after 2 weeks of frozen storage, there were practically no further changes during the subsequent storage. Such a sharp

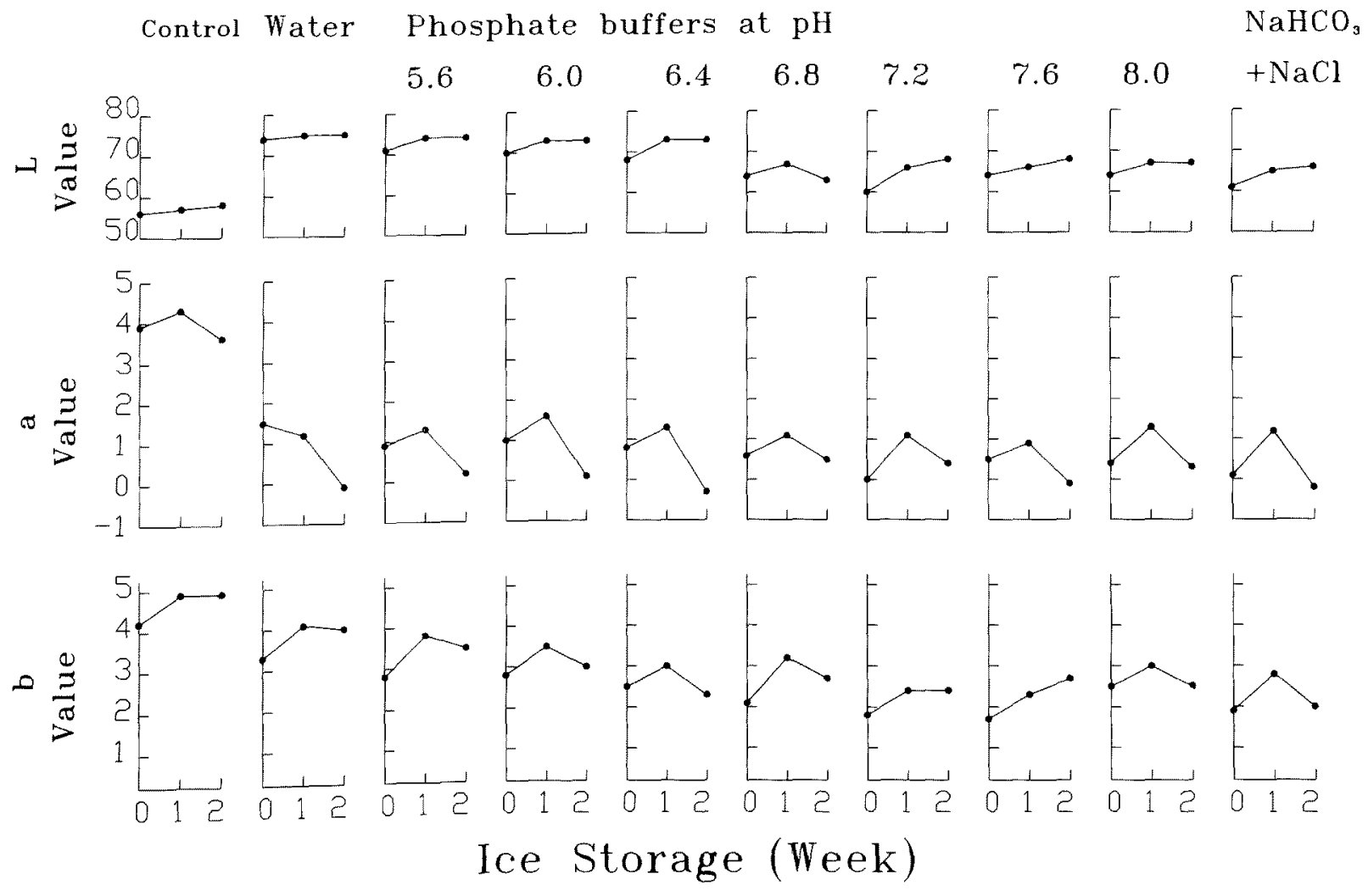

Fig. 2. Effects of washing media and storage period on the Hunter's tristimulus values ( $\mathbf{L}, \mathbf{a}$ and $\mathbf{b})$ of the washed mince of ice-stored milkfish. Moisture content of the washed mince was adjusted to $82 \%$ after centrifugation. Control: unwashed mince. 


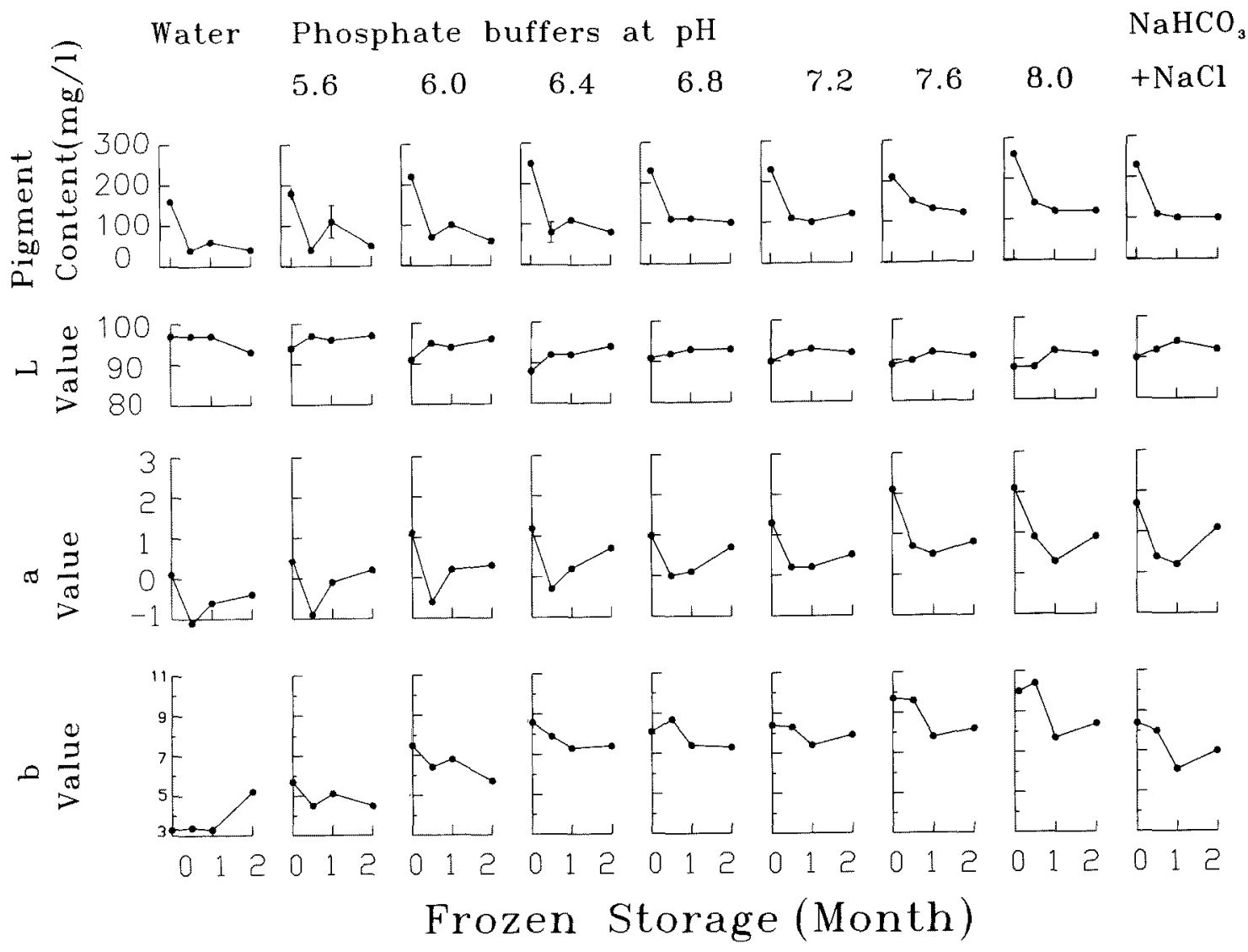

Fig. 3. Effects of washing media and storage period on the pigment content and Hunter's tristimulus values (L, $\mathbf{a}$ and $\mathbf{b})$ of the extracts from frozenstored milkfish.

decrease could be due to the insolubilization of myoglobin as described above. Chow et al. ${ }^{18-20)}$ found that myoglobin from bluefin tuna was partly insolubilized when stored frozen, due to the structural changes of myoglobin by freezing and thawing. Incidentally, the values of metMb\% were $19.1,29.2$ and $32.9 \%$ for the samples stored frozen for 0,2 weeks and 1 month, respectively. It follows that myoglobin oxidation proceeded even during the frozen storage as was the case with the ice storage.

Except in the case of water washing, $\mathbf{L}$ values tended to be slightly higher compared to those of fresh fish, while a and $\mathbf{b}$ values were lower than those of the fresh one. Among the washing media tested, the phosphate buffers of higher $\mathrm{pH}$ and alkaline wash could extract a larger amount of pigment, and as a result, $\mathbf{a}$ and $\mathbf{b}$ values increased and the $\mathbf{L}$ value decreased.

The $\mathbf{L}$ values of the washed mince from the frozenstored fish were higher than those of unwashed mince, irrespective of the washing media used (Fig. 4). However, as the $\mathrm{pH}$ value of washing media was raised, the $\mathbf{L}$ value tended to decrease. Such a tendency is quite similar to that observed for the ice-stored fish (Fig. 2). When the mince was washed by water or $\mathrm{pH} 5.6-6.0$ buffers, $L$ values were higher than 70 , indicating that the washing by the acidic media resulted in lighter colored mince. Though the efficiency of pigment extraction decreased during storage as shown in Fig. 3, the effect of washing on the color of washed mince was not obvious. The lightness of the washed mince from frozen-stored fish was roughly comparable to that of the ice-stored fish. There were no significant differences in the a value between the fresh and frozen samples. The a values of washed mince from the ice-stored fish showed a temporary increase regardless of the $\mathrm{pH}$ values of washing media (Fig. 2), but the extent of the fluctuation in the a value was much less in the case of frozen-stored fish. The $\mathbf{b}$ value decreased gradually during prolonged frozen storage.

\section{Effect of Washing Media on the Quality of Kamaboko from Fresh Fish}

Kamaboko was tentatively prepared only from fresh samples, and the effects of the washing media on the quality of kamaboko were examined (Table 2). Though the kamaboko prepared from the unwashed mince (control) gave grade AA in the folding test, the maximum stress and deformation were $596 \mathrm{~g}$ and $1.2 \mathrm{~cm}$, respectively, and the water holding capacity was also low as judged from the amount of expressible water. Washing by any media improved the quality of kamaboko. Especially, the maximum stress and deformation were increased up to $1,317 \mathrm{~g}$ and $1.5 \mathrm{~cm}$ by washing with $\mathrm{pH} 7.2$ and 8.0 buffers, respectively, and the amount of expressible water decreased to $23 \%$ by washing with $\mathrm{pH} 7.6$ buffer and alkaline wash. On the other hand, the two parameters of gel forming ability 
Control Water Phosphate buffers at $\mathrm{pH}$

$\mathrm{NaHCO}_{3}$
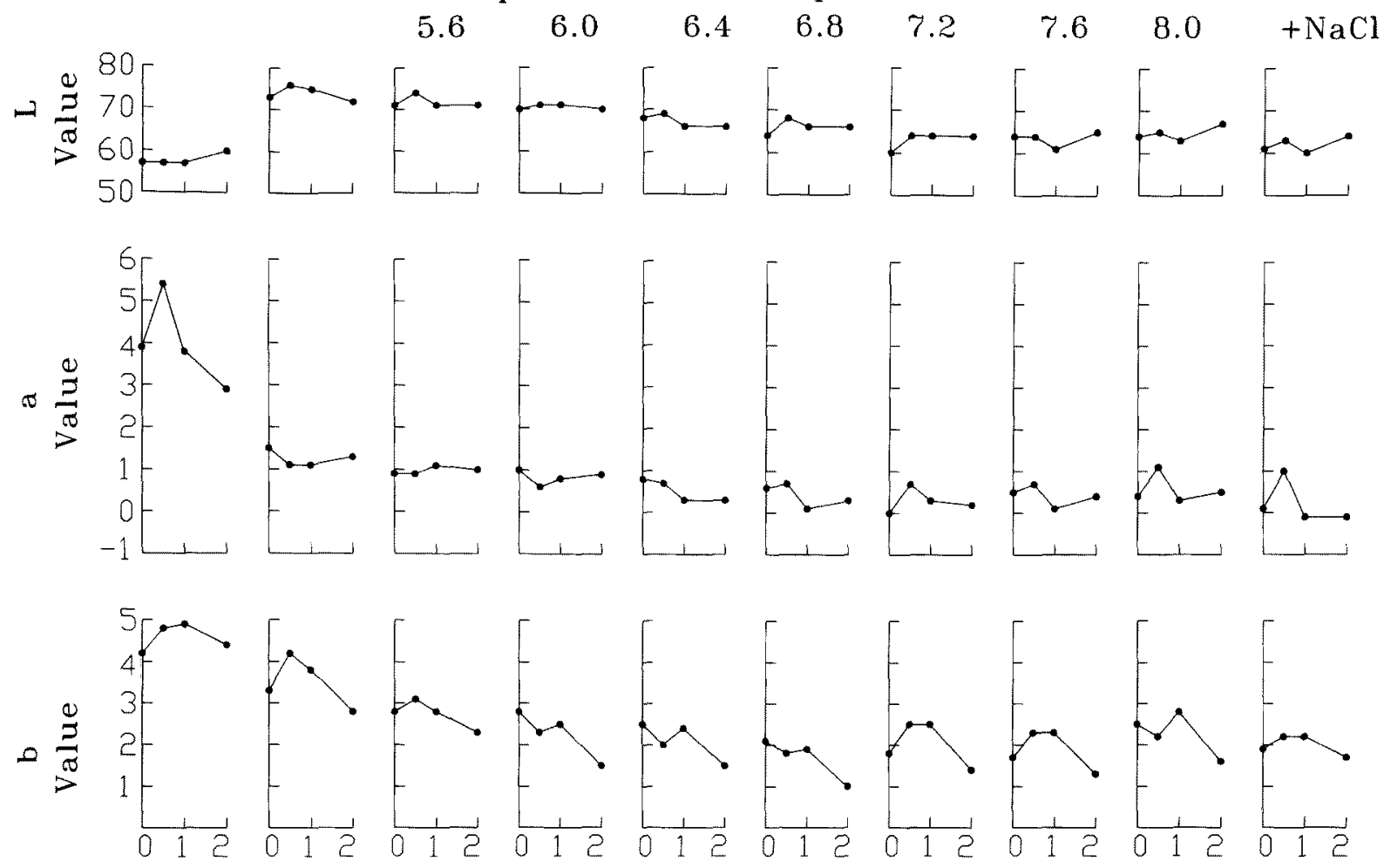

\section{Frozen Storage (Month)}

Fig. 4. Effects of washing media and storage period on the Hunter's tristimulus values ( $\mathbf{L}, \mathbf{a}$ and $\mathbf{b}$ ) of the washed mince of frozen-stored milkfish. Moisture content of the washed mince was adjusted to $82 \%$ after centrifugation. Control: unwashed mince.

Table 2. Effect of washing on the quality of kamaboko prepared from fresh milkfish

\begin{tabular}{|c|c|c|c|c|c|c|c|c|}
\hline \multirow{2}{*}{\multicolumn{2}{|c|}{ Washing media }} & \multicolumn{2}{|c|}{ Gel strength } & \multirow{2}{*}{$\begin{array}{c}\text { Expressible } \\
\text { water }(\%)\end{array}$} & \multirow{2}{*}{$\begin{array}{c}\text { Folding } \\
\text { test }\end{array}$} & \multicolumn{3}{|c|}{ Color values } \\
\hline & & Max. stress (g) & Deformation $(\mathrm{cm})$ & & & $\mathbf{L}$ & $\mathbf{a}$ & b \\
\hline Control & & $596 \pm 69$ & $1.2 \pm 0.2$ & $30 \pm 4$ & AA & 62.5 & 6.2 & 4.9 \\
\hline Deioniz & & $814 \pm 93$ & $0.9 \pm 0.1$ & $27 \pm 2$ & AA & 66.7 & 4.2 & 2.3 \\
\hline \multicolumn{9}{|c|}{$40 \mathrm{mM}$ phosphate } \\
\hline \multirow[t]{7}{*}{ buffer } & $\mathrm{pH} 5.6$ & $1,100 \pm 82$ & $1.1 \pm 0.1$ & $32 \pm 3$ & AA & 65.9 & 4.4 & 3.1 \\
\hline & 6.0 & $1,218 \pm 71$ & $1.2 \pm 0.1$ & $32 \pm 3$ & $\mathrm{AA}$ & 66.1 & 4.5 & 2.8 \\
\hline & 6.4 & $1,277 \pm 95$ & $1.3 \pm 0.1$ & $26 \pm 2$ & AA & 64.8 & 4.2 & 2.6 \\
\hline & 6.8 & $-*_{2}$ & $1.2 \pm 0$ & $26 \pm 3$ & $\mathrm{AA}$ & 64.0 & 4.0 & 2.5 \\
\hline & 7.2 & $1,317 \pm 63$ & $1.3 \pm 0.1$ & $28 \pm 3$ & AA & 63.4 & 3.8 & 2.8 \\
\hline & 7.6 & $1,082 \pm 51$ & $1.4 \pm 0.1$ & $23 \pm 3$ & $\mathrm{AA}$ & 62.0 & 4.0 & 2.8 \\
\hline & 8.0 & $1,149 \pm 102$ & $1.5 \pm 0.1$ & $24 \pm 3$ & $\mathrm{AA}$ & 62.0 & 3.2 & 2.7 \\
\hline Alkaline & & $1,059 \pm 15$ & $1.4 \pm 0.1$ & $23 \pm 1$ & $\mathrm{AA}$ & 63.0 & 4.1 & 2.6 \\
\hline
\end{tabular}

*1 Prepared from unwashed mince. Moisture content was adjusted to $82 \%$.

*2 Data were not available.

${ }^{*} 0.2 \% \mathrm{NaHCO}_{3}-0.15 \% \mathrm{NaCl}$

were the lowest when the muscle was washed by distilled water, though the stress was increased by water washing from $596 \mathrm{~g}$ to $814 \mathrm{~g}$. The improvement of gel forming ability of milkfish by washing observed here is quite similar to the data reported by Ko and Liou. ${ }^{8}$

The $\mathbf{L}$ values were slightly higher for those washed by water and acidic media. Generally, the higher the $\mathrm{pH}$ value of the media, the lower the $\mathbf{L}$ value became. The $\mathbf{L}$ values of washed mince were dependent on the $\mathrm{pH}$ values of washing media and were in the range of 60-75 (Figs. 2 and 4), but the $\mathbf{L}$ values of kamaboko prepared from the respective minces fell in quite a narrow range (62.0-66.7). This is probably because the lightness due to myofibrillar proteins in the mince was intensified by thermal denaturation through setting and heating, and this masked the discoloration due to myoglobin. It is also likely that denaturation of 
myoglobin itself was involved in this phenomenon. However, the lightness of kamaboko reflected that of the washed mince, though the extent was much less compared to the latter. On the other hand, $\mathbf{a}$ and $\mathbf{b}$ values were decreased by washing, irrespective of the media used. No significant differences in these parameters were observed regardless of the washing media tested.

The data in Table 2 demonstrated that the quality of milkfish kamaboko was largely affected by the washing media and $\mathrm{pH}$. For fresh milkfish, washing by $\mathrm{pH} 7.2$ medium gave the highest maximum stress. Washing by $\mathrm{pH} 8.0$ medium was also considered to be effective to maximize the deformation, though the lightness of kamaboko is slightly sacrificed. Further studies are, however, necessary to establish the effects of storage condition on the gel forming ability of milkfish muscle.

Acknowledgments This work was supported by the National Science Council of Republic of China, under Grant NSC 82-0115-C-022-0002.

\section{References}

1) Taiwan Fisheries Bureau: Fisheries Yearbook Taiwan Area in 1990 Taiwan Fisheries Bureau, Department of Agriculture and Forestry, Provincial Government of Taiwan. p. 5 (1991).

2) C. C. Lee, C. C. Cheng, and M. C. Lee: The post-harvest treatment and its processing status and extension of milkfish. The Proceeding of the Utilization of Milkfish Forum. Fishery Extension of National Kaohsiung Institute of Marine Technology Proceeding, 7, 1-10 (1992).

3) C. S. Chen, D. C. Hwang, and S. T. Jiang: Purification and characterization of milkfish myosin. Nippon Suisan Gakkaishi, 54, 14231427 (1988).

4) W.-C. Ko and S.-Y. Shieh: Relationship between the initial activity and thermal inactivation of Ca-ATPase from milkfish actomyosin and myosin. Fisheries Sci., 61, 369-370 (1995).

5) S. T. Jiang, D. C. Hwang, and C. S. Chen: Effect of storage temperatures on the formation of disulfides and denaturation of milkfish actomyosin. J. Food Sci., 53, 1333-1335, 1386 (1988).

6) S. T. Jiang, D. C. Hwang, and C. S. Chen: Denaturation and change in SH group of actomyosin from milkfish during storage at $-20^{\circ} \mathrm{C}$. J. Agric. Food Chem., 36, 433-437 (1988).

7) C. S. Chen, D. C. Hwang, and S. T. Jiang: Effect of storage temperature on the formation of disulfides and denaturation of milkfish myosin. J. Agric. Food Chem., 37, 1228-1231 (1989).

8) W.-C. Ko and S.-C. Liou: Thermal gelation properties of milkfish (Chanos chanos) cultured in Taiwan. Nippon Shokuhin Kogyo Gakkaishi, 41, 574-577 (1994).

9) P. D. Warriss: The extraction haem pigments from fresh meat. $J$. Food Technol., 14, 75-80 (1979).

10) C. J. Chow, Y. J. Chu, and L. C. Wang: Comparison of heme pigment extraction from tuna and round herring. The Proceeding of The Second Asian Fisheries Forum. Asian Fisheries Society, Manila, Philippines, 877-880 (1990).

11) D. I. Drabkin: Crystallographic and optical properties of human hemoglobin. A proposal for the standarization of hemoglobin. Am. J. Med., 209, 268-270 (1945).

12) $Y$. Sano and K. Hashimoto: A spectrophotometric method for the simultaneous determination of ferrous and ferric forms of myoglobin in their mixed solution. Nippon Suisan Gakkaishi, 24, 519523 (1958).

13) E. Niwa and G. Nakajima: Differences in protein structure between elastic kamaboko and brittle one. Nippon Suisan Gakkaishi, 41, 579 (1975).

14) C. J. Chow: Studies on the processing condition and the effect of additives on the texture of minced fish product from squid (Ommastrephes bartrami). Natl. Sci. Counc. Monthly, 11, 627-637 (1983).

15) T. Fujii: Texture and its instrument of surimi products of seafood. Food Sci. (Japan), 11, 81-85 (1977).

16) C. Jauregui, J. M. L. Regenstein, and R. C. Baker: A simple centrifugal method for measuring expressible moisture, a water-holding property of muscle. J. Food Sci., 46, 1271-1273 (1981).

17) A. O. A. C.: Official Method of Analysis, 14th ed., Association of Official Analytical Chemists, Washington D. C. (1984).

18) C. J. Chow, Y. Ochiai, S. Watabe, and K. Hashimoto: Autoxidation of bluefin tuna myoglobin in association with freezing and thawing. J. Food Sci., 52, 589-591 (1987).

19) C. J. Chow, Y. Ochiai, S. Watabe, and K. Hashimoto: Effect of freezing and thawing on the discoloration of tuna meat. Nippon Suisan Gakkaishi, 54, 639-648 (1988).

20) C. J. Chow, Y. Ochiai, and K. Hashimoto: Effect of freezing and thawing on the autoxidation of bluefin tuna myoglobin. Nippon Suisan Gakkaishi, 51, 2073-2078 (1985). 